\title{
Making Video News Visible: Identifying the Optimization Strategies of the Cybermedia on YouTube Using Web Metrics
}

\section{Carlos Lopezosa, Enrique Orduna-Malea \& Mario Pérez-Montoro}

To cite this article: Carlos Lopezosa, Enrique Orduna-Malea \& Mario Pérez-Montoro (2019):

Making Video News Visible: Identifying the Optimization Strategies of the Cybermedia on YouTube Using Web Metrics, Journalism Practice, DOI: 10.1080/17512786.2019.1628657

To link to this article: https://doi.org/10.1080/17512786.2019.1628657

曲制 Published online: 12 Jun 2019.

Submit your article to this journal ๘

View Crossmark data 


\title{
Making Video News Visible: Identifying the Optimization Strategies of the Cybermedia on YouTube Using Web Metrics
}

\author{
Carlos Lopezosa ${ }^{a}$, Enrique Orduna-Malea ${ }^{b}$ and Mario Pérez-Montoro ${ }^{c}$ \\ ${ }^{a}$ Department of Communication, Universitat Pompeu Fabra, Barcelona, Spain; ${ }^{\mathrm{b}}$ Department of Audiovisual \\ Communication, Documentation and History of Art (DCADHA), Universitat Politècnica de València, Valencia, \\ Spain; 'Department of Information Science and Media Studies, Universitat de Barcelona, Barcelona, Spain
}

\begin{abstract}
The main objective of this study is to identify the main SEO strategies implemented by the cybermedia's YouTube channels using a battery of web metrics at the channel and video levels. To this end, a sample comprising the ten cybermedia channels in Spain with the highest web traffic is considered. At the channel level, a significant positive correlation is found between connectivity (number of subscribers), productivity (number of videos published), and audience (number of views). At the video level, the correlation between the most viewed videos of each cybermedia reveals the presence of two families of video-level metrics: on the one hand, those related to the impact of videos (Views, Popularity, Likes, etc.) and, on the other, those related to the implementation of active SEO strategies (primarily, tags and keywords within Description fields). Results seem to confirm that SEO strategies are likely to be more effective when applied to videos that are not high quality publications or which do not address popular subject matters, characteristics that tend to attract most viewers regardless of SEO strategies employed. Finally, a set of best practices for promoting and optimizing videos on YouTube, especially tailored for the cybermedia, is proposed.
\end{abstract}

\section{KEYWORDS}

Cybermedia; YouTube; search engine optimization; video SEO; Journalism; analytic tools; web indicators; Spain

\section{Introduction}

According to the media map elaborated by Inteligencia y Media (https://www.ymedia.es/ es/mapa-de-medios), in 2018 there were at least 500 companies operating in the radio, television, press, and advertising sectors in Spain. However, the information structure in Spain is characterized by a great concentration of media power (Reig 2011), which is supported by the main communication groups (Vocento, Unidad Editorial, COPE, Planeta, Atresmedia, Mediaset España Comunicación, Imagina Media Audiovisual, Godó, Zeta, Prensa Ibérica, Joly, Hearst Magazines, Intereconomía Corporación, and Henneo).

One of the main problems of the Spanish communication media is the lack of innovation in the sector (García-Santamaría, Fernández-Beaumont, and Pérez-Bahón 2016), which is exacerbated by the currently period of digital transformation of industries. Therefore, the need to propose strategies that allow communication media the dissemination of 
content globally using all kinds of multimedia platforms (among which Youtube stands out) is more important than ever.

In particular, Journalism is becoming increasingly visual, undoubtedly the result of the growing influence of the Web (Peer and Ksiazek 2011) and, as part of this trend, in addition to having to respond to other concurrent pressures (including, web visibility, new formats, and new ways of navigating), the mainstream media have begun to launch channels on YouTube (https://www.youtube.com).

By using these video channels, the media have obtained a supplementary platform on which to disseminate their journalistic productions (Rodríguez-Martínez, Codina, and Pedraza-Jiménez 2010). But, in opting to do so, journalism needs to identify best practices to ensure it connects its audiovisual production with its target audience (Giomelakis and Veglis 2015a, 2015b; Lopezosa and Codina 2018). Such a strategy seems critical if we bear in mind the importance of YouTube as a source of information for a large number of individuals. Proof of this is that today it is ranked as the second most used search engine in the world, after Google (Spencer 2018).

Given the global popularity of YouTube, with over one billion users watching over a billion hours of video each day (https://www.youtube.com/intl/en-GB/yt/about/press), the strategies associated with search engine optimization (SEO) (Davis 2006) will undoubtedly be of massive importance in optimizing the visibility of these media channels within the ocean of content currently hosted on YouTube.

The SEO literature has been concerned for some time now with designing, proposing, developing and testing sets of indicators and tools for the study of website and web page visibility (Codina et al. 2016; García-Carretero et al. 2016) as a proxy of quality (RodríguezMartínez, Codina, and Pedraza-Jiménez 2010, 2012). These indicators have subsequently been adapted and applied to the field of Audiovisual Communication, specifically to the optimization of videos published on YouTube (Bonelli 2017; Fons 2018a). However, the optimization of the cybermedia's YouTube channels has yet to be analyzed from the perspective afforded by SEO.

The objectives of this study are therefore to identify and measure the SEO strategies being implemented by the cybermedia using a battery of metrics developed in SEO. To this end, the following research questions (RQs) are addressed:

RQ1. Do the cybermedia's YouTube channels present specific performance patterns when measured using channel-level SEO metrics?

RQ2. Do the most viewed videos published by the cybermedia use SEO actions to achieve their higher impact (as measured using video-level metrics) on YouTube?

Finally, a set of recommendations will be generated for the cybermedia so they can optimize their video visibility on YouTube.

\section{Research Background}

Most of the literature related to SEO is published by the profession on posts in their specialized blogs or on data provider websites. Given the business opportunities that characterize the SEO market and the high level of competition between practitioners, new methods and research findings are not usually published via the traditional communication channels. All of this hinders attempts at defining the research background. For this reason, this section 
undertakes its review of previous research by examining, first, the use made by the cybermedia of videos on the Web, and, second, the optimization of videos on YouTube.

\section{Cybermedia and Videos on the Web}

Video has established itself as one of the predominant formats of consumer content on the Web, which has meant that search engines are increasingly taking video content into account in their results. An analysis conducted by Searchmetrics (https://www. searchmetrics.com) on universal searches confirms this trend, showing that a significant number of results correspond to video, both for mobile (23\%) and desktop searches (22\%) (Grundmann and Bench-Capon 2018). To this we should add that the role played by websites offering videos is enjoying rapid growth (McClure 2011). According to My Web Presenters (https://mwpdigitalmedia.com), online video represents half of all mobile traffic in 2018, and it is expected that video traffic will constitute $81 \%$ of all web traffic by 2021, both for mobile and desktop environments (Kakkar 2018).

Given the rise and influence of video, it is not surprising that YouTube stands as the second most popular website in the world according to the Alexa ranking (https://www. alexa.com/topsites), with over 20 billion visits per day (https://www.similarweb.com/ website/youtube.com\#overview). The prominence of YouTube is also reflected in its market share, reaching $92 \%$, with the remaining $8 \%$ being shared primarily between Vimeo (https://vimeo.com), Dailymotion (https://www.dailymotion.com/es) and Vevo (https://www.vevo.com) (Jarboe 2018).

For this reason, the cybermedia have cast their lot with the video format and the creation of channels on YouTube to boost and promote their production. In so doing, the media have adopted an entrepreneurial approach, characterized essentially by the perception of this platform (as well as of others, including Google and Facebook) as a business opportunity tool (Kalogeropoulos and Nielsen 2017).

These developments have led to the emergence of a line of research that examines relations between YouTube and the video-news published by the cybermedia. Within this line, studies of the interactivity between journalist and audience stand out, and include content analysis of video comments (Al Nashmi et al. 2017) and user engagement with a news items (Ksiazek, Peer, and Lessard 2016). Other studies focus on the quality of video production and content, where the use of different metrics (such as, number of views) is associated with different indicators of quality (Peer and Ksiazek 2011; OrdunaMalea and Alonso-Arroyo 2017).

The purpose of this study is specifically to address one such metric-the visibility of videos on YouTube-which is critical to any assessment of the potential success or failure of a video, and which might, though not necessarily, be indirectly related to its quality. The fact that the cybermedia appear to be taking actions to optimize the positioning of their videos (and, hence, their visibility) could be having an influence on their relative success, regardless of their quality.

\section{Optimization of Videos on YouTube}

YouTube uses a different positioning algorithm to that employed by Google (Fons 2018a; Jarboe 2018), enabling the platform to order the videos shown in the search results against 
a specific query (Yu 2015). The objective of the algorithm is to help users find the videos that most closely match their needs (as expressed via their queries), based on their perceived relevance (Jarboe 2018). To do this, YouTube orders the most relevant videos for a query using a wide number of parameters, among which one recursive metric stands out: the viewing time. This means that videos that have proved to be more attractive to other users are rewarded, reinforcing what sociologist Robert Merton called the "Matthew effect".

To attain a prominent position for popular queries (those that carry the main web traffic to websites), the administrators of YouTube channels have to apply different SEO strategies. As such, SEO on YouTube (coined as SEOtube) comprises the set of procedures that are applied to the videos uploaded to this platform to obtain greater visibility, not only on YouTube but on other search engines too, including Google, Bing, etc. These optimization practices must, moreover, be implemented rapidly, since the first 48-72 hours after a video has been deposited are crucial for obtaining the best positions in the ranking (Bonelli 2017; Spencer 2018).

Conceptual examples, in the form of procedures and recommendations for SEO on YouTube, have been provided by many of the leading scholars in the field of video positioning (see below). Although these recommendations vary from one author to another, a number of common elements can be generalized as constituting best practices. Here, an overview of the current state of the art of SEOtube techniques is provided.

Since search engines are not yet able to interpret images directly, YouTube operates at the metadata level, providing a group of textual descriptions (including the title and keywords) that can guide the search engine with regards to a video's iconic and semantic content (Bonelli 2017). The main YouTube metadata fields are those providing details about the video title, its description and duration, the thumbnail, and the name of the uploaded video file (Litsa 2016). The better these metadata are optimized, the more likely the videos are to rank higher in the search results.

The "video title" should seek to represent its content with precision, while at the same time striving to be both forceful and catchy (Litsa 2016; Jarboe 2018; Smarty 2018). Some recommend using between 65 and 70 of the 100 characters permitted (Boachie and Bench-Capon 2017; Hollingsworth 2017), or to include at least five words in it (Dean 2018; Fons 2018b; Spencer 2018). Of these five words, one or more should be the keyword that the author wants to use for positioning the video (Choudhari and Bhalla 2015; Yu 2015; Fons 2018b; Dennis 2017).

When uploading a video to YouTube it is also essential to take the "description" into account. This field has a limit of 5000 characters and should seek to awaken the user's interest (Choudhari and Bhalla 2015). Some authors claim that for SEO it is best to use a brief video description (Boachie and Bench-Capon 2017; Hollingsworth 2017); however, there seems to be a broader consensus that the description should be as complete as possible, somewhere between 250 and 700 words (Dean 2018; Fons 2018b; Jarboe 2018; Smarty 2018; Spencer 2018). The description needs to be optimized as if it were a blog article, since it is what YouTube and Google will use to help determine the context of the video and, hence, its rank (Dean 2018). Some authors further recommend that the "description" field include the keyword in the first paragraph, and that it be repeated between two and four times in the remainder of the text (Dean 2018), and that it include at least one external link targeting the website of the 
video's creator (Hollingsworth 2017), social networks (Spencer 2018) and/or an index with time links to allow the user to go to a specific moment of the video when that link is clicked (Dean 2018).

The "tags" constitute another key element of SEO optimization on YouTube, helping users and search engines understand a video's content by categorizing it by its keyword (Bonelli 2017). Since YouTube indexes up to 270 characters in its tags (Jarboe 2018), the keywords in the tag should be representative of the uploaded video (Hollingsworth 2017; Dean 2018). Google actually recommends using a mix of tags that describe the video both generically and specifically (Jarboe 2018). However, although the majority of authors recommend their use (since they help both YouTube and Google understand what a video is about), there is no consensus about the right number. Some favor using very few (Boachie and Bench-Capon 2017; Dean 2018), while others recommend using between 10 and 20 tags (Bonelli 2017).

The "thumbnail" (a random frame of an uploaded video that allows users to see a quick capture of its content) can also be optimized. Here, experts recommend creating a custom thumbnail with impact that will encourage users to click on the video, rather than using the default thumbnail provided by YouTube. In so doing, authors should also use texts and graphics that complement the thumbnail image (Spencer 2018). Finally, it is recommended to upload high resolution-1280×720 pixels-thumbnails (Jarboe 2018; Smarty 2018).

When a video is posted on YouTube, it is automatically transcribed in text format so that the search engines are able to understand its content. This "transcript text" can be reviewed and edited; it is advisable not to trust automated transcriptions since they will contain errors (Spencer 2018). Additionally, keywords should be included in a consistent fashion throughout the transcript (Litsa 2016), as this will help the search engines learn more about the video content.

A further automated element provided by YouTube is that of the "automatic translation" of the video, in the form of subtitles. Both Hollingsworth (2017) and Spencer (2018) recommend its use if the goal is to give the video international visibility.

Metadata fields, however, are not the only elements that influence a video's search results and, as such, they are not the only elements that can be optimized to ensure videos have greater visibility and occupy a higher ranking. Among these other elements we find:

Comments: are a good indication that the uploaded video interested other users (Fons 2018b). Therefore, activating them and interacting with the audience improves visibility (Yu 2015; Hollingsworth 2017; Fons 2018b; Jarboe 2018).

Playlists: allow the collection, organization and publication of multiple videos at the same time, thus increasing the amount of time spent viewing and optimizing visibility (Jarboe 2018). There is a broad consensus on the SEO value of playlists since they allow videos to be grouped according to keywords, giving this set of videos greater visibility (Spencer 2018). Playlists also increase the chances of appearing at the top of the SERP for a greater variety of words or phrases, and they also improve viewer engagement since the whole set of videos can be viewed consecutively, thus adding more viewing minutes (Smarty 2018).

Categories: help YouTube recommend a video based on content criteria and user behavior (Hollingsworth 2017). Currently, the following categories are in use: cars and vehicles; 
beauty and fashion; comedy; education; entertainment; family entertainment; cinema and animation; food; video games; tips and style; music; news and politics; NGOs and activism; people and blogs; pets and animals; science and technology; sports; and travel and events (YouTube Creators 2018).

Duration: should not be too short (Yu 2015; Hollingsworth 2017) and ought to comply with the fifteen golden seconds strategy (Dean 2018), which means engaging the user/ viewer in the first 15 seconds of the video, during which time the problem/need must be posed in order to retain the user/viewer (Boachie and Bench-Capon 2017; Fons 2018b) and so boost the rate of engagement.

Interactivity: is more psychological in nature and, importantly, includes the "call to action" - that is, promoting the video in a persuasive way so users will subscribe, comment, mark it as a "favorite", like or dislike, watch other related videos, etc. (Yu 2015; Boachie and Bench-Capon 2017; Spencer 2018). Elements that can be used in this call to action include "cards" and "final screens", which allow the incorporation within the video of up to four interactive elements to promote content, playlists, the channel and the website (Boachie and Bench-Capon 2017; Jarboe 2018).

Other SEOtube techniques have been described, but have not been accepted by the entire community. Some such strategies are:

- Activation of distribution rights, thereby allowing users to share their videos in the form of embedded content on external platforms (Hollingsworth 2017).

- Deactivation of age restrictions, provided the content justifies it (Hollingsworth 2017).

- Promotion of uploaded video via social networks and websites (Yu 2015; Litsa 2016; Smarty 2018).

- Sharing of videos on websites with heavy traffic (such as Quora, Alexa, etc.) and with news aggregators (such as Meneame or Reddit) (Dean 2018; Fons 2018b).

- Use of relevant keywords in video file name, avoiding unintelligible generic names that do not represent the reality and content of the video (Litsa 2016).

However, we can also find a wide variety of bad practices to improve the positioning of the videos, among which the Clickbait stands up (Qu et al. 2018). This technique consists in inflating users' expectations about the content through the title, so that the user Links/ clicks on the videos. Despite this technique is not necessarily bad itself, it ceases to be legitimate when using deceptive, controversial, or simply fake content to attract web traffic. Literature has already proved that YouTube it is not able to recognize the clickbait (Zannettou et al. 2018), therefore it is capable of recommending deceptive videos to users. Other common bad practices (such as video cloaking, content farming or fraudulent link building) diminish the accuracy of metrics obtained by specific videos in Youtube.

\section{Method}

To address the specific study objectives identified above, we examined a sample of cybermedia YouTube portals. More specifically, the ten most regularly consulted cybermedia channels in Spain were selected according to comScore (as of March 2018) and Alexa Rank (as of July 2018). While comScore (https://www.comscore.com) is the official measure of monthly audience counts for Spain's digital newspapers, Alexa Rank (https:// 
www.alexa.com/siteinfo), owned by Amazon, provides web traffic rankings. Our use of these sources, despite possible biases and shortcomings, provides us with a sample of cybermedia channels that is characterized by its high web traffic, important for identifying the SEO strategies of the leading news media firms in one country when publishing their videos.

The cybermedia channels included in our sample together with their comScore and Alexa rankings are shown in Table 1 . Additionally, we identify their official accounts on YouTube (channel or user).

We next undertook an analysis of the positioning of each of these YouTube channels, in general, and of the video with the highest number of views for each of the ten cybermedia channels, in particular. To do this, we used the vidIQ tool (https://vidiq.com), SEO audit software specifically for YouTube videos. VidIQ currently provides coverage for more than 30,000 YouTube channels, including those of such companies as AOL, eBay and Time Inc., which makes it especially suitable tool for the objectives of this study.

The battery of web indicators included in the analysis (both at channel and video levels) are identified in Table 2 and their scope defined.

The analysis of all ten portals was carried out on 9 July 2018. All data extracted from vidIQ was subsequently exported to a spreadsheet where they were statistically analyzed with the XLSTAT application. Spearman correlation $(a<0.05)$ and principal component analysis (Spearman PCA) were carried out to respond to RQ2.

\section{Results}

First, the results for the different cybermedia channels are shown. Second, the impact measures for the videos with the highest number of views on each channel are included. Finally, based on these results, a series of recommendations are proposed for the optimization of videos on YouTube.

\section{Cybermedia YouTube Channels}

The performance metrics (Age, Subscribers, Videos published, overall number of Views, and Playlists) at the channel level are shown in Table 3.

Age: The oldest YouTube channel analyzed is Periodista Digital, registered on 4 November 2005, followed by 20 Minutos, which opened on 21 August 2006, while the youngest

Table 1. Sample of Spanish cybermedia channels with high web traffic.

\begin{tabular}{lccll}
\hline Cybermedia & Comscore Rank & Alexa Rank & \multicolumn{1}{c}{ URL } & YouTube \\
\hline El Mundo & 1 & 16 & elmundo.es & CanalELMUNDOes \\
El País & 2 & 14 & elpais.com & elpaiscom \\
La Vanguardia & 3 & 34 & lavanguardia.com & lavanguardia \\
ABC & 4 & 32 & abc.es & Not found \\
El Confidencial & 5 & 36 & elconfidencial.com & Elconfidencialtv \\
20 Minutos & 6 & 40 & 20minutos.es & 20minutos \\
El Periódico & 7 & 111 & elperiodico,com & elperiodico \\
${ }^{*}$ Ok Diario & 8 & 9 & okdiario.com & UCf6W-gNFCIPt_XtQ6P44NTg \\
${ }^{*}$ El Español & 9 & 15 & elespanol.com & UClvqcSPbQBynjq230v9_yw \\
Periodista Digital & 10 & 288 & periodistadigital.com & periodistadigital \\
\hline
\end{tabular}

*Cybermedia with old YouTube channel account (without a friendly URL). 
Table 2. Battery of search engine optimization (SEO) metrics.

\begin{tabular}{|c|c|c|c|}
\hline Indicator & Scope (Unit) & Channel & Video \\
\hline Age & Days since the channel was launched (Days) & $\mathrm{X}$ & \\
\hline Description type & Type of description provided to a YouTube channel (Short/Long/No description) & $X$ & \\
\hline Links in Description & Existence of outlinks included in the description field (Hyperlinks) & $X$ & \\
\hline Subscribers & Total number of users subscribed to the channel (Users subscribed) & $X$ & \\
\hline Videos & Total number of videos published on the channel (Videos) & $X$ & \\
\hline Playlist & Number of playlists where the channel is reproduced (Playlists) & $X$ & \\
\hline $\begin{array}{l}\text { Total Channel } \\
\text { Views }\end{array}$ & Number of views of all videos published on a channel (Views) & $\mathrm{X}$ & \\
\hline Top Video Views & $\begin{array}{l}\text { The number of views for the video with the highest number of views on a } \\
\text { channel (Views) }\end{array}$ & & $\mathrm{X}$ \\
\hline Tags in Title & Number of tags included in the title of the most viewed video (Tags) & & $\mathrm{X}$ \\
\hline Tag Popularity & $\begin{array}{l}\text { The popularity of the tag is quantified according to the number of times the tag } \\
\text { is used in a YouTube video (Score from } 0 \text { to 5) }\end{array}$ & & $\mathrm{X}$ \\
\hline Keywords in Title & Number of keywords included in the title of the most viewed video (Keywords) & & $x$ \\
\hline Tags & Number of tags used to describe the most viewed video (Tags) & & $\mathrm{X}$ \\
\hline SEO Score & $\begin{array}{l}\text { Combined indicator based on video optimization and the probability of } \\
\text { promotion in related videos, search, recommended videos, etc. (Score from } 0 \\
\text { to } 100 \text { ) }\end{array}$ & & $\mathrm{X}$ \\
\hline Likes/Dislikes & Number of times a video receives a liked/dislike (Likes/Dislikes) & & $\mathrm{X}$ \\
\hline Popularity & $\begin{array}{l}\text { Score based on interactions and visits relative to other YouTube videos (Score } \\
\text { from } 0 \text { to 100) }\end{array}$ & & $\mathrm{x}$ \\
\hline Performance & $\begin{array}{l}\text { Measures the quality of video optimization and its visibility in YouTube search } \\
\text { results (Score from } 0 \text { to 50) }\end{array}$ & & $\mathrm{x}$ \\
\hline Interactivity & $\begin{array}{l}\text { Measure of interaction calculated as a percentage of total visits (Good/Average/ } \\
\text { Bad) }\end{array}$ & & $\mathrm{X}$ \\
\hline Tags & Tags used in the analyzed video (Tags) & & $\mathrm{X}$ \\
\hline $\begin{array}{l}\text { Keywords in } \\
\text { Description }\end{array}$ & Number of keywords included in the description field (Keywords) & $\mathrm{X}$ & $X$ \\
\hline Keyword popularity & $\begin{array}{l}\text { The popularity of the keyword is quantified according to the number of times } \\
\text { the keyword is included in a search for a video (Score from } 0 \text { to } 5 \text { ) }\end{array}$ & & $x$ \\
\hline External hyperlinks & Number of external web pages pointing to the most viewed video (Hyperlinks) & & $\mathrm{X}$ \\
\hline
\end{tabular}

YouTube channel analyzed is Ok Diario, registered on 8 February 2016. This gives a range of 10 years for the channels studied here and which has to be taken into account in the follow-up to this research.

Subscribers: El País boasts the highest number of users with a subscription to its YouTube channel $(237,614)$, giving an average of 62.01 new subscribers per day since its inception. In contrast, Ok Diario has the fewest subscribers (6081). Finally, El Periódico, operating third oldest cybermedia channel, has the lowest rate of new subscribers/day (1.45).

Table 3. YouTube channel performance metrics.

\begin{tabular}{|c|c|c|c|c|c|c|c|c|c|}
\hline \multirow[b]{2}{*}{ Channel } & \multirow[b]{2}{*}{ Age } & \multicolumn{2}{|c|}{ Subscribers } & \multicolumn{2}{|c|}{ Videos } & \multicolumn{3}{|c|}{ Views } & \multirow{2}{*}{$\begin{array}{c}\text { Playlists } \\
\text { Total }\end{array}$} \\
\hline & & Total & Per Day & Total & Per Day & Total & Per Day & Per Video & \\
\hline El Mundo & 1876 & 9414 & 5.02 & 187 & 0.10 & $3,281,241$ & 1749.06 & $17,546.74$ & 7 \\
\hline El País & 3832 & 237,614 & 62.01 & 9439 & 2.46 & $168,625,958$ & $44,004.69$ & $17,864.81$ & 70 \\
\hline La Vanguardia & 4199 & 126,514 & 30.13 & 6,547 & 1.56 & $105,476,262$ & $25,119.38$ & $16,110.63$ & 109 \\
\hline$A B C$ & N/A & N/A & $\mathrm{N} / \mathrm{A}$ & $\mathrm{N} / \mathrm{A}$ & $\mathrm{N} / \mathrm{A}$ & N/A & N/A & $\mathrm{N} / \mathrm{A}$ & $\mathrm{N} / \mathrm{A}$ \\
\hline El Confidencial & 2694 & 18,442 & 6.85 & 3061 & 1.14 & $12,705,541$ & 4716.24 & 4150.78 & 48 \\
\hline 20 Minutos & 4340 & 25,221 & 5.81 & 790 & 0.18 & $13,005,191$ & 2996.59 & $16,462.27$ & 20 \\
\hline El Periódico & 4271 & 6209 & 1.45 & 1077 & 0.25 & $6,441,992$ & 1508.31 & 5981.42 & 11 \\
\hline Ok Diario & 882 & 6081 & 6.89 & 419 & 0.48 & $3,113,587$ & 3530.14 & 7431.00 & 9 \\
\hline El Español & 1280 & 6304 & 4.93 & 511 & 0.40 & $2,499,273$ & 1952.56 & 4890.95 & 10 \\
\hline Periodista Digital & 4630 & 25,274 & 5.46 & 4162 & 0.90 & $22,267,224$ & 4809.34 & 5350.13 & 18 \\
\hline
\end{tabular}

N/A. No data available. 
Videos: In terms of productivity, El País ranks first (with a total of 9439 videos uploaded) followed by La Vanguardia (6547). At the bottom of the ranking, representing the least productive channel, is El Mundo (with 187 videos).

Views: El País $(168,625,958$ views) and La Vanguardia $(105,476,262)$ are the cybermedia channels that have attracted the highest number of total views, followed at some distance by Periodista Digital $(22,267,224)$. However, when we normalize this value according to the number of videos published, both El Mundo (17,546.7 views per video) and 20 Minutos $(16,462.3)$ present notable rates.

Playlist: On average, the number of playlists that include the cybermedia channels in our sample is low. La Vanguardia (109 playlists) and El País (70) top the rankings for this parameter.

The correlation between all the channel-level metrics shows a strong relationship between Subscribers, Videos uploaded, overall number of Views and Playlists (Table 4). The Age variable, though exhibiting a moderate positive correlation with the remaining variables, seems to be less related (i.e., age does not necessarily correspond to high performance).

The relative position of each cybermedia channel according to each of the channellevel metrics is shown in Figure 1. As can be seen, El País and La Vanguardia stand out as having the greatest impact.

Description Field: All the cybermedia channels include a very short, basic channel description. Table 5 shows the main target URLs included in this field. As we can see, the existence of a hyperlink to the official website (seven of the nine channels include this link) is common practice. As for social platforms, links to Facebook, Twitter and Google+ are the most common.

\section{Most Viewed Videos}

The corresponding metrics (Views, Popularity, Performance, Links, Interaction average, Interactivity, and SEO Score) for the most viewed video on each cybermedia channel are shown in Table 6.

Views: The most viewed videos show a huge statistical deviation $(S D=2,107,188)$ and statistical range $(5,903,201)$. La Vanguardia stands out as hosting the most viewed video ( $R=6,346,638$ views).

Popularity: The average popularity score is moderately high (72.1 out of 100) with a low statistical range (14.6). The most viewed video on Periodista Digital obtains the highest popularity score (79.1), while the lowest corresponds to Ok Diario (64.5).

Performance: Four channels (El Español, La Vanguardia, Ok Diario, and Periodista Digital) score 0 on this parameter. In contrast, the most viewed video in El Periódico obtains a high score (33.8 out of 50$)$.

Table 4. Correlation matrix (Spearman) between channel-level metrics.

\begin{tabular}{|c|c|c|c|c|c|}
\hline Variables & Age & Subscribers & Videos & Views & Playlists \\
\hline Age & 1 & 0.53 & 0.55 & 0.67 & 0.48 \\
\hline Subscribers & 0.53 & 1 & $* 0.80$ & *0.92 & *0.80 \\
\hline Videos & 0.55 & *0.80 & 1 & *0.88 & *0.90 \\
\hline Views & 0.67 & *0.92 & ${ }^{*} 0.88$ & 1 & *0.85 \\
\hline Playlist & 0.48 & $* 0.80$ & ${ }^{*} 0.90$ & ${ }^{*} 0.85$ & 1 \\
\hline
\end{tabular}

*Values are different from 0 with a significance level alpha $=0.05$. 


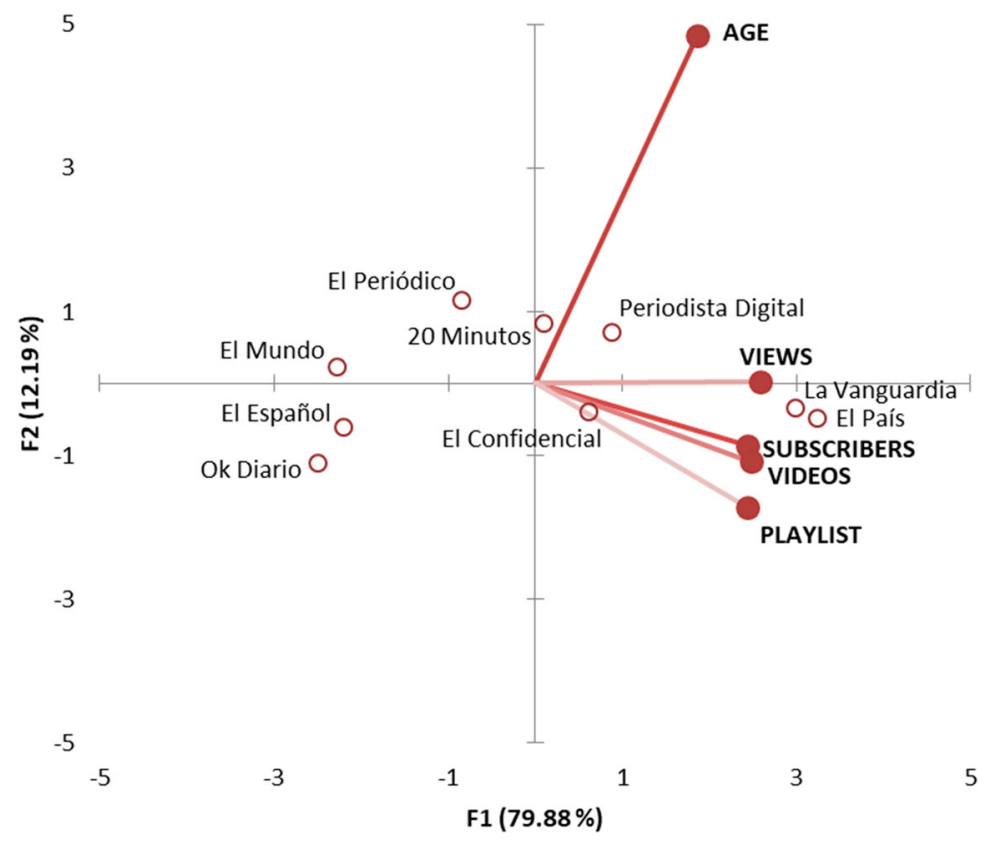

Figure 1. Principal component analysis of channel-level metrics.

Interactivity: The statistical deviation of this parameter is also high $(S D=13,330)$ with a high range $(37,011)$, reflecting considerable variability between the videos. The distribution of likes and dislikes per video also varies greatly. El Periódico (97\%), 20 Minutos (96.2\%) and El País (95.7\%) receive most interactions in the form of likes, whereas El Mundo (67.7\%) and Periodista Digital (45.0\%) receive a significant share of dislikes from their users.

External Hyperlinks: In general, the number of inlinks that the most viewed videos receive is low $(\bar{x}=355)$, the maximum being 1500 (Periodista Digital), and the minimum just 24 (El País).

SEO Score: On average, this value is low among the nine videos analyzed $(\bar{x}=18.9)$. El Periódico's most viewed video records the highest score (70.5 out of 100). In contrast, Periodista Digital's records the lowest score (0), demonstrating how one of the most viewed videos in our sample (in this case with a total number of views of $4,354,404$ ) can obtain a score of zero both on Performance and on SEO.

Table 5. Hyperlinks included in the channel description field.

\begin{tabular}{lccccccc}
\hline Cybermedia & Official Website & External Website & Facebook & Google+ & Instagram & Pinterest & Twitter \\
\hline El Mundo & $\mathrm{X}$ & & $\mathrm{X}$ & $\mathrm{X}$ & & & $\mathrm{X}$ \\
El País & $\mathrm{X}$ & $\mathrm{X}$ & $\mathrm{X}$ & & $\mathrm{X}$ \\
lavanguardia.com & $\mathrm{X}$ & $\mathrm{X}$ & $\mathrm{X}$ & $\mathrm{X}$ & $\mathrm{X}$ \\
El Confidencial & $\mathrm{X}$ & $\mathrm{X}$ & $\mathrm{X}$ & & $\mathrm{X}$ \\
20 Minutos & $\mathrm{X}$ & $\mathrm{X}$ & $\mathrm{X}$ & & $\mathrm{X}$ \\
El Periódico & & $\mathrm{X}$ & $\mathrm{X}$ & $\mathrm{X}$ & $\mathrm{X}$ & $\mathrm{X}$ \\
Ok Diario & $\mathrm{X}$ & & & $\mathrm{X}$ & & $\mathrm{X}$ \\
El Español & $\mathrm{X}$ & & $\mathrm{X}$ & & $\mathrm{X}$ & $\mathrm{X}$ \\
Periodista digital & $\mathrm{X}$ & $\mathrm{X}$ & $\mathrm{X}$ & & & \\
\hline
\end{tabular}


Table 6. Metrics for most viewed videos I: performance.

\begin{tabular}{|c|c|c|c|c|c|c|c|c|c|}
\hline \multirow[b]{2}{*}{ Cybermedia } & \multirow[b]{2}{*}{ Views } & \multirow[b]{2}{*}{ Popularity } & \multirow[b]{2}{*}{ Performance } & \multirow[b]{2}{*}{ Links } & \multirow[b]{2}{*}{ Interaction } & \multicolumn{3}{|c|}{ Interactivity } & \multirow[b]{2}{*}{ SEO Score } \\
\hline & & & & & & Total & $\begin{array}{l}\text { Likes } \\
(\%)\end{array}$ & $\begin{array}{c}\text { Dislikes } \\
(\%)\end{array}$ & \\
\hline El Periódico & 694,627 & 70.2 & 33.8 & 136 & Good & 2989 & 97.0 & 3.0 & 70.5 \\
\hline El Mundo & $1,261,460$ & 73.8 & 15 & 298 & Good & 31,000 & 32.3 & 67.7 & 22.5 \\
\hline El País & $3,905,797$ & 68.7 & 5.4 & 24 & Bad & 28,200 & 95.7 & 4.3 & 18.7 \\
\hline El Español & 443,437 & 68.5 & 0 & 111 & Average & 3900 & 66.7 & 33.3 & 14.4 \\
\hline La Vanguardia & $6,346,638$ & 70.8 & 0 & 262 & Bad & 9500 & 67.4 & 32.6 & 13.8 \\
\hline Ok Diario & 588,277 & 64.5 & 0 & 108 & Average & 7100 & 56.3 & 43.7 & 13.7 \\
\hline 20 Minutos & $1,799,978$ & 67.1 & 5 & 390 & Bad & 14,549 & 96.2 & 3.8 & 11.9 \\
\hline El Confidencial & 855,225 & 72.1 & 5 & 367 & Average & 10,200 & 80.4 & 19.6 & 5 \\
\hline Periodista Digital & $4,354,404$ & 79.1 & 0 & 1500 & Bad & 40,000 & 55.0 & 45.0 & 0 \\
\hline
\end{tabular}

A strong positive and statistically significant correlation is found between the number of Views and the number of Likes $(r=0.72)$. Additionally, the correlation between Views and Popularity $(r=0.48)$ is notable. The correlation between the remaining metrics, however, is very weak (Table 7) and, surprisingly, even negative in some cases, e.g., the correlation between the SEO Score and the number of hyperlinks $(r=-0.6)$, on the one hand, and Likes $(-0.32)$, on the other.

Figure 2 shows the relative distances between each of the most viewed videos following the principal component analysis. These results reveal the existence of different performance dimensions. In fact, each video stands out in relation to one specific metric, which means it tends not to stand out in relation to the others.

Note that the data depicted in Figure 2 refer solely to the most viewed video for each cybermedia, which may bias the results. For this reason, descriptive statistics (median, minimum, maximum, and standard deviation) of the SEO and Performance scores for the top ten most viewed videos on each channel are included in Table 8 as of October 2018. As can be seen, the Performance scores are low to moderate for all channels. In fact, $47.8 \%$ (43 videos) obtain a score of " 0 ", reflecting the low engagement of the most viewed videos published by the Spanish cybermedia. The SEO scores, on the other hand show considerable variability in the standard deviation, reflecting marked differences not only between the channels but also between the videos published by the same channel.

Figure 3 includes a box plot of the SEO and Performance scores, which confirms the high level of variability among the top 90 viewed videos as well as the existence of topperformers as outliers in the distribution.

The multidimensionality highlighted in Figure 2 is also confirmed when determining the strategies employed in relation to tags and keywords (Table 9). As we can see, each

Table 7. Correlation matrix (Spearman) between video-level metrics.

\begin{tabular}{|c|c|c|c|c|c|c|c|}
\hline Variables & Views & Popularity & Performance & Hyperlinks & Likes & Dislikes & SEO Score \\
\hline Views & 1 & & & & & & \\
\hline Popularity & 0.48 & 1 & & & & & \\
\hline Performance & -0.07 & 0.16 & 1 & & & & \\
\hline Hyperlinks & 0.40 & 0.57 & -0.07 & 1 & & & \\
\hline Likes & $* 0.72$ & 0.33 & 0.17 & 0.33 & 1 & & \\
\hline Dislikes & 0.26 & 0.54 & -0.39 & 0.28 & 0.18 & 1 & \\
\hline SEO Score & -0.27 & -0.12 & 0.64 & -0.60 & -0.32 & -0.28 & 1 \\
\hline
\end{tabular}

*Values are different from 0 with a significance level alpha $=0.05$. 


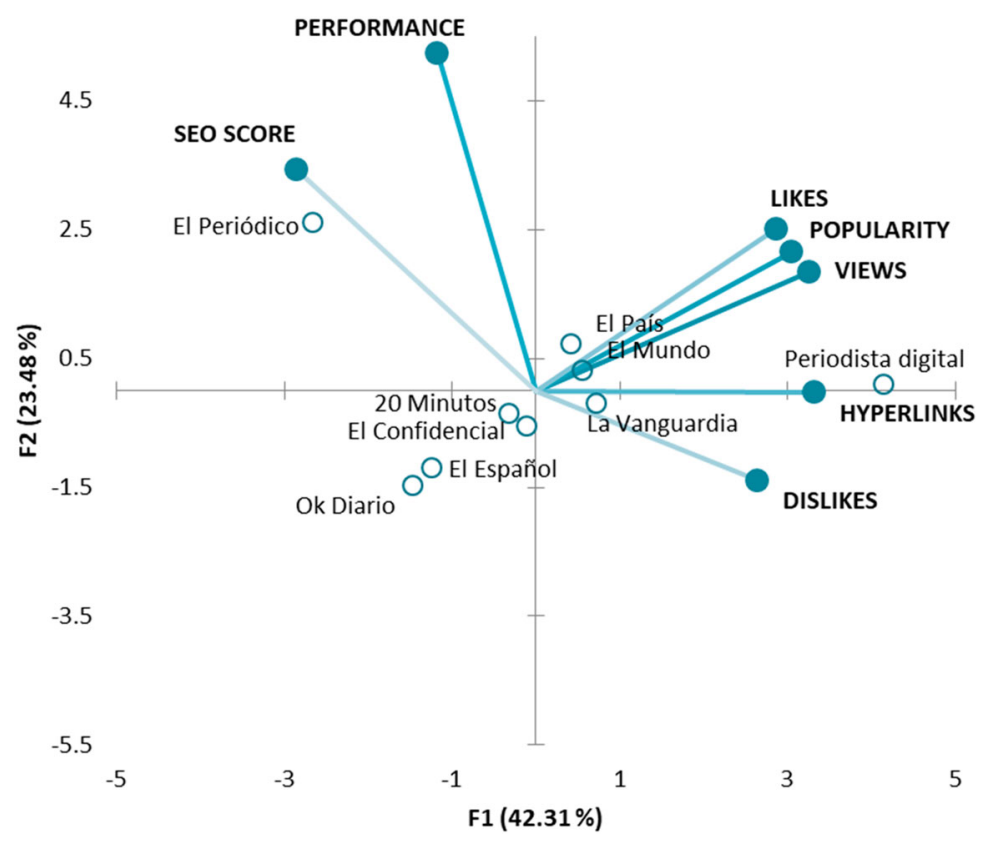

Figure 2. Principal component analysis of video-level metrics corresponding to the most viewed videos of each cybermedia channel.

of the nine most viewed videos on each of the channels adopts a particular technique, albeit that some do not employ any strategy (e.g., El Confidencial) or focus on just one specific parameter (e.g., Periodista Digital). Some of the most viewed videos are classified (4), others are not (5); some use classified tags (5), others do not (4). The popularity of Title tags also varies considerably (ranging from 0 to 4 points). Overall, the nine most viewed videos do not present any coherent pattern in their use of descriptive tags and keywords.

\section{Discussion and Conclusions}

\section{RQ1: Cybermedia YouTube Channels}

Spain's cybermedia channels exhibit very different characteristics and behaviors on YouTube. The numbers of videos published, views received and subscribers vary widely

Table 8. SEO and Performance scores for top 10 most viewed videos for each cybermedia.

\begin{tabular}{|c|c|c|c|c|c|c|c|c|}
\hline \multirow[b]{2}{*}{ Cybermedia } & \multicolumn{4}{|c|}{ SEO Score } & \multicolumn{4}{|c|}{ Performance } \\
\hline & Median & Min & Max & SD & Median & Min & Max & SD \\
\hline El Mundo & 18.2 & 7.0 & 53.5 & 14.7 & 0.0 & 0.0 & 28.9 & 9.2 \\
\hline El País & 19.9 & 0.0 & 70.0 & 26.9 & 5.0 & 0.0 & 26.3 & 10.7 \\
\hline La Vanguardia & 11.1 & 0.0 & 65.5 & 24.7 & 2.5 & 0.0 & 25.0 & 7.7 \\
\hline El Confidencial & 20.1 & 1.6 & 52.1 & 20.0 & 9.0 & 0.0 & 31.3 & 11.0 \\
\hline 20 Minutos & 14.2 & 3.2 & 40.1 & 12.3 & 0.0 & 0.0 & 10.0 & 3.4 \\
\hline El Periódico & 29.6 & 8.5 & 65.8 & 20.2 & 10.0 & 0.0 & 28.8 & 9.2 \\
\hline Ok Diario & 13.7 & 0.0 & 18.7 & 6.3 & 0.0 & 0.0 & 10.0 & 3.5 \\
\hline El Español & 16.0 & 6.3 & 30.5 & 8.9 & 0.0 & 0.0 & 7.2 & 3.0 \\
\hline Periodista Digital & 19.9 & 0.0 & 46.2 & 14.7 & 5.0 & 0.0 & 10.2 & 4.0 \\
\hline
\end{tabular}



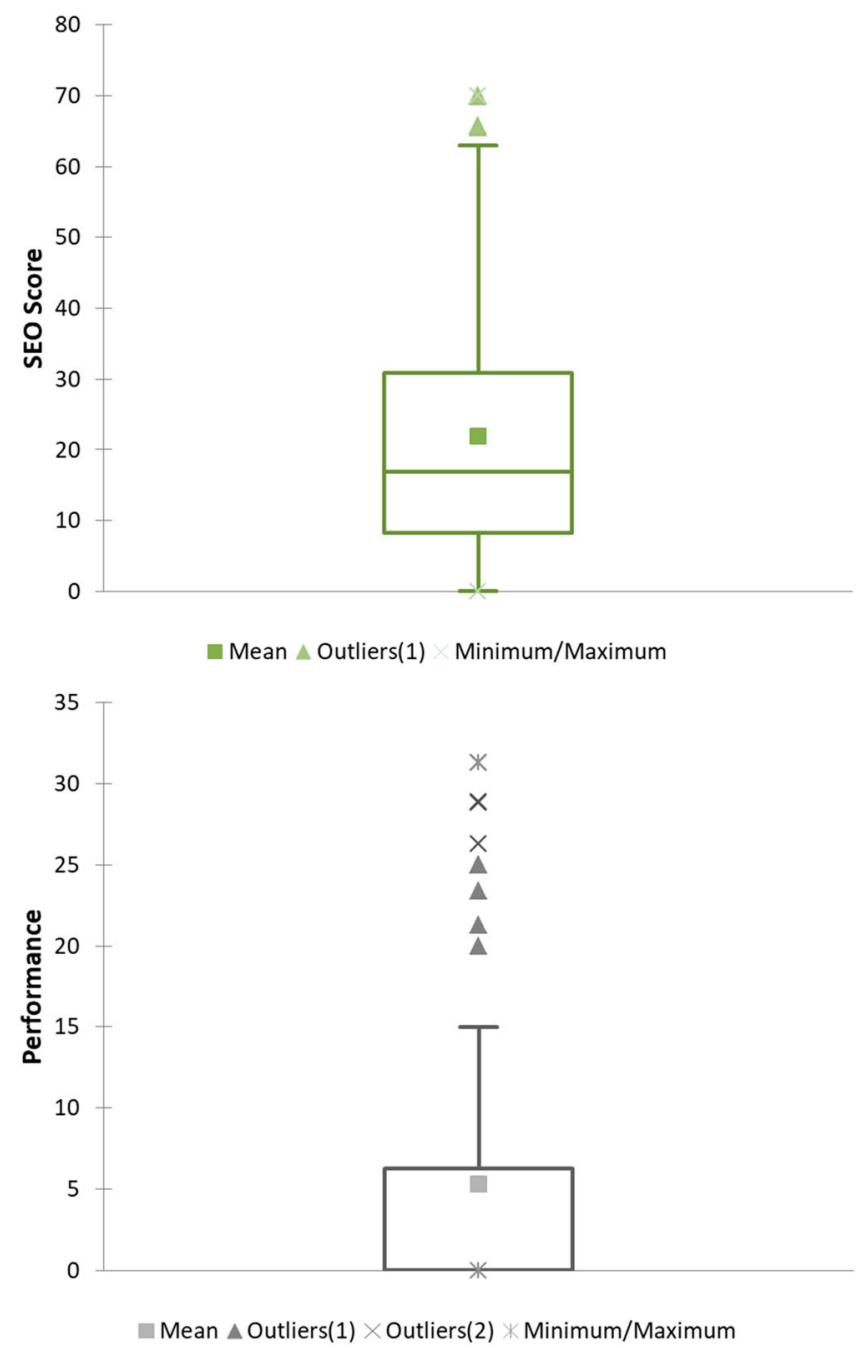

Figure 3. Box plot of the SEO (top) and Performance scores (bottom) $(n=90)$.

from one cybermedia to another. The results confirm, however, the presence of a strong positive and significant correlation between the number of videos published, the total views received, and the number of subscribers, regardless of the age of the channel. In this sense, age in itself is not necessarily associated with high metrics in the rest of the parameters, which suggests that the latter could, to some extent, be associated with the quality or success of the published contents. Among these parameters, Playlists seem to have a strong impact; however, their low order of magnitude could limit their use.

\section{RQ2: Highest Optimized Videos}

The most viewed videos published by each of the cybermedia channels analyzed do not exhibit common performance patterns. Our correlation results identify a cluster of SEO metrics (SEO and Performance scores) that differ from the remaining parameters 
Table 9. Metrics for most viewed videos II: keywords and tags.

\begin{tabular}{|c|c|c|c|c|c|c|c|c|c|}
\hline Video & Video Tags & Title Keywords & Title Tags & Title Tags Popularity & Classified Tags & Tag Points & Description Keywords & Description Links & Category \\
\hline El Mundo & 8 & 1 & 1 & 0 & 3 & 0 & 45 & 6 & News \& Politics \\
\hline El País & $\mathrm{N} / \mathrm{A}$ & 1 & 2 & 3 & 1 & 0.1 & 17 & 6 & News \& Politics \\
\hline La Vanguardia & 6 & 1 & 1 & 3 & 1 & 0.1 & 55 & 4 & Science \& Technology \\
\hline El Confidencial & 1 & 0 & 0 & 0 & 1 & 0 & 0 & 0 & News \& Politics \\
\hline 20 Minutos & $\mathrm{N} / \mathrm{A}$ & 1 & 1 & 0 & 1 & 0 & 32 & 5 & $\mathrm{~N} / \mathrm{A}$ \\
\hline El Periódico & 8 & 4 & 2 & 4 & 0 & 2.8 & 18 & 0 & $\mathrm{~N} / \mathrm{A}$ \\
\hline Ok Diario & 2 & 2 & 0 & 0 & 0 & 0 & 13 & 1 & N/A \\
\hline El Español & 10 & 1 & 2 & 3 & 0 & 0 & 11 & 0 & $\mathrm{~N} / \mathrm{A}$ \\
\hline Periodista Digital & 0 & 0 & 0 & 0 & 0 & 0 & 145 & 0 & $\mathrm{~N} / \mathrm{A}$ \\
\hline
\end{tabular}


(Impact) and which do not present a strong correlation with each other. For example, we find that Periodista Digital's most viewed video achieves the highest Popularity score (79.1) but at the same time the lowest SEO score (0).

This may point to the presence of two families of video-level metrics: on the one hand, those related to the impact of videos (Views, Popularity, Likes, etc.) and, on the other, those related to the implementation of active SEO strategies (primarily, tags and keywords within Description fields). Since Impact and SEO metrics do not necessarily correlate with each other, this may explain why videos with greater online visibility are not necessarily the ones to which more SEO strategies have been applied, and vice versa. Although clearly correlation does not imply causation, it goes some way to explaining the relationship between the metrics.

These results should, however, be treated with caution, since only a small sample of cybermedia channels and videos has been considered, and this behavior may not be manifest in another sample of videos. Indeed, these findings should be understood as applying only to Spain's cybermedia.

Yet, an analysis of the most viewed videos of Spain's leading cybermedia channels provides insights into the SEO strategies implemented. In fact, the results show that only one cybermedia channel (EI Periódico) has actively employed SEO strategies. However, its actions cannot-at least to date-be associated with the impact of its publications, since we cannot know when these actions were implemented (within 72 hours of dissemination) and the effect of other external variables.

The fact that only the most viewed videos have been considered here constitutes a further limitation of this study, because the cybermedia channels might have begun to apply active SEO strategies for videos published at a subsequent date. For this reason, an analysis of all videos published by a cybermedia (or at least a significant sample) is necessary for a better understanding of the SEO strategies adopted and their effect on impact. This study should be seen as an exploratory analysis using the most viewed videos, that is, as a case study given the special characteristics of these videos. The information included in Table 8 (with data expanded to include the top ten videos for each cybermedia) opens the door to an exploration of the differences in the performance of videos published by the same cybermedia.

Future studies should also take into account the rankings obtained by videos according to specific queries. This would provide a better understanding of the effects of active SEO strategies on the visibility of videos on the search engine results page of both YouTube and Google, and the role of this visibility as an intermediary of impact. Moreover, the inclusion of more metrics, both at the video (e.g., shares and comments) and channel levels (e.g., subscriber influence) would further understanding of video and channel performance and its correlation with active SEO strategies and SEO-related metrics.

Finally, the point in time at which data are collected should also be taken into account. The data gathered here show that SEO scores can change over time, at times rising (e.g., the most viewed video published by EI Pais presented an SEO score of 18.7 as of July 2018, but this had risen to 22.3 as of October 2018) and at others falling (the most viewed video published by El Mundo presented an SEO score of 22.5 as of July 2018 , but this had fallen to 17.5 as of October 2018).

Otherwise, this research is focused on the video/channel-side (a quantitative performance approach), and not on the organization-side, whose social media policies, budgets, 
national laws or social and cultural environment may influence in the dissemination practices. In this sense, an ethnographic study may help to shed light on the reasons of the use or not of SEO strategies in Youtube. Moreover, the incorporation of qualitative analyses (such as interviews with professionals involved in the creation and dissemination of videos from the Cybermedia) may enrich future research and provide a better understanding of the Cybermedia behavior on Youtube.

\section{Best Practices for Optimizing Videos on YouTube}

Our results indicate that the most viewed videos achieved their status regardless of the use made of active SEO strategies, suggesting that the reasons behind their success were either the quality of the publication, the subject covered (controversial subjects often attract more interest), or the characters appearing in the video (e.g., famous people). For example, the most viewed video on La Vanguardia was a story about breastfeeding older children, while on El Mundo was about King Felipe VI.

SEO strategies should, however, be more effective when applied to videos that do not have these characteristics of quality of publication or popularity of subject matter (that is, the majority of uploaded videos). In this sense, and based on the results obtained, we propose a set of best practices and recommendations aimed at optimizing the visibility of videos on YouTube and Google, especially for cybermedia.

- Video title: should include the main keyword, be between 65 and 70 characters long, and contain about five words.

- Description: should not be too brief. The keyword should be included in the first paragraph and then repeated between two and four times in the rest of the description. The description should carry external links to a personal website, social networks, and an index with time links, and include calls to action.

- Tags: should use keyword tags that describe both the generic and specific content of the video.

- Thumbnail: should be clear, of high resolution, and persuade viewer to click on the video.

- Transcript: should be generated manually and include keywords throughout.

- Translation: subtitle option should be activated to ensure the video appears in global searches.

- Comments: should be activated to promote interactivity, and author should respond to them.

- Playlists: should be created around thematic keywords. The videos on the playlists can include publications from other channels as well.

- Categories: select the category that best characterizes the video.

- Interactivity: viewers should be called on to "like" the video, comment on it, subscribe to the channel, etc.

- Duration: should not be too short but importance is its rate of engagement (i.e., viewing time).

\section{Disclosure Statement}

No potential conflict of interest was reported by the authors. 


\section{Funding}

This work was supported by Ministerio de Economía y Competitividad [grant number CSO201564955-C4-2-R].

\section{References}

Al Nashmi, Eisa, Michael North, Terry Bloom, and Johanna Cleary. 2017. "'Boots on the Ground?': How International News Channels Incorporate User-Generated Content into Their YouTube Presence." International Communication Gazette 79 (8): 746-768. doi:10.1177\%2F1748048517707404.

Boachie, Pius, and Stephen Bench-Capon. 2017. "How to Optimize Your Videos for YouTube: Bestpractice tips." Search Engine Watch. Searchmetrics Whitepaper. https://searchenginewatch.com/ 2017/11/23/how-to-optimize-your-videos-for-youtube-best-practice-tips/.

Bonelli, Sherry. 2017. "YouTube SEO: How to Find the Best Traffic-Generating Keywords." Search Engine Land. https://searchengineland.com/youtube-seo-find-best-traffic-generating-keywords275690.

Choudhari, Krishna, and Vinod Bhalla. 2015. "Video Search Engine Optimization Using Keyword and Feature Analysis." Procedia Computer Science 58: 691-697.

Codina, Lluís, Mar Iglesias-García, Rafael Pedraza, and Lucía García-Carretero. 2016. Search Engine Optimization and Online Journalism: The SEO-WCP Framework. Barcelona: Universitat Pompeu Fabra.

Davis, Harold. 2006. Search Engine Optimization. Sebastopol: O'Reilly Media.

Dean, Brian. 2018. "YouTube SEO: How to Rank YouTube Videos in 2018." Backlinko. https://backlinko. com/how-to-rank-youtube-videos.

Dennis, Andrew. 2017. "How to Rank \#1 on YouTube Search in 30 Days [Case Study]." Search Engine Land. https://searchengineland.com/rank-1-youtube-search-30-days-case-study-281198.

Fons, Romuald. 2018a. "Cómo ser Youtuber en el 2018." https://romualdfons.com/como-seryoutuber/.

Fons, Romuald. 2018b. "SEO en Youtube: Cómo posicionar vídeos en 2018." https://romualdfons. com/seo-en-youtube/.

García-Carretero, Lucía, Llluís Codina, Javier Díaz-Noci, and Mar Iglesias-García. 2016. “Herramientas e indicadores SEO: características y aplicación para análisis de cibermedios." El profesional de la información 25 (3): 497-504. doi:10.3145/epi.2016.may.19.

García-Santamaría, José, José Fernández-Beaumont, and Félix Pérez-Bahón. 2016. "La nueva prensa online en España: Diversidad de proyectos pero modelos de negocio poco innovadores." In: SEP Sociedad Española de Periodística, Salamanca.

Giomelakis, Dimitrios, and Andreas Veglis. 2015a. "Employing Search Engine Optimization Techniques in Online News." Studies in Media and Communication 3 (1). doi:10.11114/smc.v3i1.683.

Giomelakis, Dimitrios, and Andreas Veglis. 2015b. "Investigating Search Engine Optimization Factors in Media Websites, the Case of Greece." Digital Journalism, 379-400. doi:10.1080/21670811.2015. 1046992.

Grundmann, Jan, and Stephen Bench-Capon. 2018. “Universal Search 2018: It's a Mobile World After All." Search Metrics. https://www.searchmetrics.com/knowledge-base/universal-search-study/.

Hollingsworth, Sam. 2017. "YouTube SEO from Basic to Advanced: How to Optimize Your Videos." Search Engine Journal. https://www.searchenginejournal.com/youtube-seo-video-optimization/ 260757/.

Jarboe, Greg. 2018. "Video SEO for Universal Search: Tips, Tools \& Techniques to Get Found." Search Engine Journal. https://www.searchenginejournal.com/video-seo-for-universal-search/261159.

Kakkar, Deepasha. 2018. "How Videos Generate Quick SEO Results." Search Engine Watch. https:// searchenginewatch.com/2018/02/19/how-videos-generate-quick-seo-results/.

Kalogeropoulos, Antonis, and Rasmus Nielsen. 2017. "Investing in Online Video News." Journalism Studies. doi:10.1080/1461670X.2017.1331709.

Ksiazek, Thomas, Limonr Peer, and Kevin Lessard. 2016. "User Engagement with Online News: Conceptualizing Interactivity and Exploring the Relationship between Online News Videos and User Comments." New Media \& Society 18 (3): 502-520. doi:10.1177/1461444814545073. 
Litsa, Tereza. 2016. "12 Video SEO Tips to Help Improve Your Search Rankings." Search Engine Watch. https://searchenginewatch.com/2016/08/24/12-video-seo-tips-to-improve-your-rankings/.

Lopezosa, Carlos, and Lluís Codina. 2018. "Análisis de posicionamiento en medios de comunicación con herramientas SEO. Cobertura informativa de los premios Óscar 2017." Barcelona: Serie editorial DigiDoc-EPI. http://www.elprofesionaldelainformacion.com/documentos/Analisis_posicion amiento_medios_comunicacion.pdf.

McClure, Marji. 2011. "ABCs of Online Video: Building a Strategy." EContent 34 (8): 22-26.

Orduna-Malea, Enrique, and Adolfo Alonso-Arroyo. 2017. Cybermetric Techniques to Evaluate Organizations Using Web-Based Data. Cambridge: Chandos Publishing.

Peer, Limor, and Thomas Ksiazek. 2011. "YouTube and the Challenge to Journalism: New Standards for News Videos Online." Journalism Studies 12 (1): 45-63.

Qu, Jiani, Anny M. Hißbach, Tim Gollub, and Martin Potthast. 2018. Towards Crowdsourcing Clickbait Labels for YouTube Videos. Aachen: HCOMP.

Reig, Ramón. 2011. Los dueños del periodismo: claves de la estructura mediática mundial y de España. Barcelona: Editorial Gedisa. ISBN: 9788497846189.

Rodríguez-Martínez, Ruth, Lluís Codina, and Rafael Pedraza-Jiménez. 2010. "Cibermedios y web 2.0: modelo de análisis y resultados de aplicación." El profesional de la información 19 (1): 35-44.

Rodríguez-Martínez, Ruth, Lluís Codina, and Rafael Pedraza-Jiménez. 2012. "Indicadores para la evaluación de la calidad en cibermedios: análisis de la interacción y de la adopción de la Web 2.0." Revista española de documentación científica 35 (1): 61-93.

Smarty, Ann. 2018. "5 YouTube Optimization Tips to Improve Your Video Rankings." Search Engine Watch. https://searchenginewatch.com/2018/03/02/5-youtube-optimization-tips-to-improveyour-video-rankings/.

Spencer, Stephan. 2018. "YouTube SEO 101." Search Engine Land. https://searchengineland.com/ youtube-seo-101-289416.

YouTube. 2018. "YouTube Creators." https://creatoracademy.youtube.com/page/browse.

Yu, Jim. 2015. "Video Optimization: Do Not Underestimate the Power of YouTube." Search Engine Land. https://searchengineland.com/video-optimization-not-underestimate-power-youtube234618.

Zannettou, Savvas, Sotirios P. Chatzis, Kostantinos Papadamou, and Michael Sirivianos. 2018. "The Good, the Bad and the Bait: Detecting and Characterizing Clickbait on YouTube." 2018 IEEE Security and Privacy Workshops (SPW) (2018): 63-69. 